\title{
Generalization of pain-related fear based on conceptual knowledge
}

Citation for published version (APA):

Meulders, A., Vandael, K., \& Vlaeyen, J. W. S. (2017). Generalization of pain-related fear based on conceptual knowledge. Behavior Therapy, 48(3), 295-310. https://doi.org/10.1016/j.beth.2016.11.014

Document status and date:

Published: 01/05/2017

DOI:

10.1016/j.beth.2016.11.014

Document Version:

Publisher's PDF, also known as Version of record

Document license:

Taverne

Please check the document version of this publication:

- A submitted manuscript is the version of the article upon submission and before peer-review. There can be important differences between the submitted version and the official published version of record.

People interested in the research are advised to contact the author for the final version of the publication, or visit the DOI to the publisher's website.

- The final author version and the galley proof are versions of the publication after peer review.

- The final published version features the final layout of the paper including the volume, issue and page numbers.

Link to publication

\footnotetext{
General rights rights.

- You may freely distribute the URL identifying the publication in the public portal. please follow below link for the End User Agreement:

www.umlib.nl/taverne-license

Take down policy

If you believe that this document breaches copyright please contact us at:

repository@maastrichtuniversity.nl

providing details and we will investigate your claim.
}

Copyright and moral rights for the publications made accessible in the public portal are retained by the authors and/or other copyright owners and it is a condition of accessing publications that users recognise and abide by the legal requirements associated with these

- Users may download and print one copy of any publication from the public portal for the purpose of private study or research.

- You may not further distribute the material or use it for any profit-making activity or commercial gain

If the publication is distributed under the terms of Article $25 \mathrm{fa}$ of the Dutch Copyright Act, indicated by the "Taverne" license above, 


\title{
Generalization of Pain-Related Fear Based on Conceptual Knowledge
}

\author{
Ann Meulders \\ Kristof Vandael \\ University of Leuven \\ Johan W.S. Vlaeyen \\ University of Leuven \\ Maastricht University
}

Increasing evidence suggests that pain-related fear is key to the transition from acute to chronic pain. Previous research has shown that perceptual similarity with a pain-associated movement fosters the generalization of fear to novel movements. Perceptual generalization of pain-related fear is adaptive as it enables individuals to extrapolate the threat value of one movement to another without the necessity to learn anew. However, excessive spreading of fear to safe movements may become maladaptive and may lead to sustained anxiety, dysfunctional avoidance behaviors, and severe disability. A hallmark of human cognition is the ability to extract conceptual knowledge from a learning episode as well. Although this conceptual pathway may be important to understand fear generalization in chronic pain, research on this topic is lacking. We investigated acquisition and generalization of concept-based pain-related fear. During acquisition, unique exemplars of one action category (CS+; e.g., opening boxes) were followed by pain, whereas exemplars of another action category (CS-; e.g., closing boxes) were not. Subsequently, spreading of pain-related fear to novel exemplars of both action categories was tested. Participants learned to expect the pain to occur and reported more pain-related fear to the exemplars of the CS+ category compared with those of the CS- category. During

This work was conducted at the University of Leuven (KU Leuven), Belgium.

Address correspondence to Ann Meulders, Ph.D., Department of Psychology, University of Leuven, Tiensestraat 102, Box 3726, 3000 Leuven, Belgium; e-mail: ann.meulders@ppw.kuleuven.be.

0005-7894/C 2016 Association for Behavioral and Cognitive Therapies. Published by Elsevier Ltd. All rights reserved. generalization, fear and expectancy generalized to novel exemplars of the CS+ category, but not to the CS- category. This pattern was not corroborated in the eyeblink startle measures. This is the first study that demonstrates that pain-related fear can be acquired and generalized based on conceptual knowledge.

Keywords: pain-related fear; acquisition; generalization; categorybased learning; associative learning

THE ABILITY TO LEARN which stimuli in the environment signal threat has an important adaptive advantage, because it enables us to initiate appropriate defensive responses that protect us from future harm (Vlaeyen, 2015). Nevertheless, adaptive learners face the challenge of how to deal with variations in the appearances of signaling stimuli. Stimulus generalization (Honig \& Urcuioli, 1981; Kalish, 1969) allows individuals to extrapolate the predictive value of one stimulus to perceptually similar stimuli and minimizes the necessity to learn everything anew. As a consequence, the advanced capacity to detect similarities between unique but related stimuli fosters swift adaptation to a dynamic environment.

Pain is a vital motivator in learning because it typically alerts the individual of impending or actual bodily threat. It has been shown that associative learning is crucially involved in the acquisition of fear of movement-related pain (Meulders, Vansteenwegen, \& Vlaeyen, 2011). In particular, using a voluntary joystick movement (VJM) 
paradigm, Meulders and colleagues (2011) showed that after (repeated) pairing of a painful electrocutaneous stimulus (unconditioned stimulus [pain-US]) with an initially neutral joystick movement (conditioned stimulus [CS]), this movement (CS+) elicited protective responses such as fear and avoidance (conditioned response [CR]), whereas another neutral joystick movement (CS-) that was not paired with pain did not evoke such CRs. Differential pain-related fear learning was apparent in self-reports and psychophysiological measures (startle eyeblink measure), as well as behavior (movement-onset latency) - that is, participants reported more fear in response to the CS+ than to the CS-, showed elevated startle responses to the CS+ compared with the CS-, and were slower in initiating a movement that was painful $\left(\mathrm{CS}_{+}\right)$than one that was not (CS-). For example, if a person performs a bending exercise $\left(\mathrm{CS}_{+}\right)$during yoga class and gets a shooting pain in the back (pain-US), this person might start to associate bending movements with pain, learn that yoga is dangerous, and begin to avoid going to yoga class altogether (CRs). From an associative learning perspective, this fear of movement-related pain might extend to a range of novel movements resembling this original pain-associated bending movement (i.e., more similar movements may induce more fear/avoidance). For example, this person might also become afraid to bend over to pick up an object and start to avoid a wide range of bending-related movements.

This type of fear generalization is typically referred to as perceptual pain-related fear generalization. Previous research in healthy participants has shown that fear spreads selectively to novel movements that have a perceptual feature in common with the original CS+ but not to movements having a feature in common with the CS- (Meulders \& Vlaeyen, 2013). More specifically, after being trained with a joystick movement straight to the left (CS+) that was followed by pain and a joystick movement straight to the right (CS-) that was not followed by pain (or vice versa), spreading of fear to four novel diagonal movements (generalization stimuli [GSs]) was tested. More specifically, participants were requested to perform novel movements directed to the left-top, the left-bottom, the right-top, and the right-bottom corners of the computer screen. Results confirmed that when the straight movement to the left served as the $\mathrm{CS}_{+}$, the diagonal movements to the left $(\mathrm{GS}+)$ elicited more fear measured with both self-report and startle amplitude than did the diagonal movements to the right (GS-). However, when the $\mathrm{CS}_{+}$was the straight movement to the right, the response pattern was reversed (Meulders \& Vlaeyen, 2013). In another study (Meulders, Vandebroek, Vervliet, \& Vlaeyen, 2013), we again trained participants with joystick movement to the left followed by pain, and joystick movements to the right not followed by pain (or vice versa), and tested novel intermediate movements lying between the CS+ and the CS-. The results corroborate previous findings at least in the startle eyeblink measures. More specifically, we showed a pain-related fear generalization gradient-that is, there was a linear decrease in startle amplitudes for GSs approaching the original CS-. Another study using a left-right hand judgment conditioning paradigm with pictures of hand postures as CSs and a painful electrocutaneous stimulus as the pain-US showed a similar gradient at least in the verbal measures (fear and expectancy; Meulders, Harvie, Moseley, \& Vlaeyen, 2015). In this study, one hand posture (CS+; e.g., extreme hand flexion) was consistently paired with pain and another hand posture (CS-; e.g., extreme hand extension) was not. During generalization, we tested the spreading of fear and US-expectancy to a set of novel hand postures (GSs) with six grades of perceptual similarity to the CS+. Results confirmed that novel GSs that were more similar to the CS+ triggered more pain-related fear and US-expectancy than did those more similar to the CS-. Taken together, accumulating evidence suggests that pain-related fear can spread based on perceptual similarity.

A certain degree of fear generalization is adaptive, but excessive generalization to technically safe stimuli may become maladaptive and pathological. In a replication of Meulders and Vlaeyen (2013), we demonstrated that patients with fibromyalgia syndrome do not show selective fear generalization like healthy pain-free controls, but overgeneralize their fear to all novel (diagonal) movements (GSs). In a hand pain scenario contingency learning task with hand postures as cues and the words "pain" and "no pain" as outcomes, participants were asked to rate the likelihood that a fictive hand pain patient would feel pain when moving the hand into certain postures (Meulders et al., 2014). One hand posture (e.g., extreme hand flexion) was consistently paired with the word "pain" and another hand posture (e.g., extreme hand extension) was paired with "no pain." During generalization, we tested the spreading of pain expectancy to a set of novel hand postures (GSs) with six grades of perceptual similarity to the pain-associated hand posture. Unilateral chronic hand pain patients showed flatter, asymmetric generalization gradients compared with healthy pain-free controls, with higher pain expectancy ratings for novel postures that were more similar to the CS-. At the CS+ side of the gradient, pain expectancy ratings did not differ between patients and controls, indicating a lack of safety learning rather than excessive fear in response to actual threat. 
Taken together, accumulating evidence suggests that adaptive pain-related fear generalization based on perceptual similarity occurs in a healthy population, but that maladaptive overgeneralization characterizes chronic pain populations.

Humans also possess the ability to abstract conceptual details of a learning episode, which allows them to generalize conditioned fear behavior between physically dissimilar stimuli that are semantically related, a process known as categorybased fear conditioning (Dunsmoor \& Murphy, 2015). The involvement of higher-order cognitions (i.e., cognitions requiring a certain degree of abstract thinking) such as conceptual knowledge or category membership in fear generalization has been demonstrated by Dunsmoor, Martin, and LaBar (2012). Typically, the term "exemplars" is used to refer to low-level, specific members (e.g., hammer) belonging to a superordinate category (e.g., tools) that signifies a higher, more abstract level within a classification system. In the Dunsmoor et al. (2012) study, $50 \%$ of the basic-level exemplars of one superordinate category (i.e., tools) were paired with an aversive shock, whereas exemplars of another category (i.e., animals) were not. The results showed category-specific anticipatory skin conductance responses and shock expectancy ratings. In another study, the investigators showed category-specific increases in brain activity in the visual cortex and fear-learning networks, further corroborating the idea that humans can learn to associate fear with an entire category despite the heterogeneity in the physical appearance of stimuli (Dunsmoor, Kragel, Martin, \& LaBar, 2013). Based on the parallels between pain-related fear in chronic pain conditions and other types of pathological fear in anxiety disorders, concept-based fear learning might affect the spreading of fear and avoidance in pain conditions as well (Dymond, Dunsmoor, Vervliet, Roche, \& Hermans, 2015). If the person in our previous example experienced a shooting pain in the back, but rather than associate it with a specific movement during the yoga class, attributed it to yoga as a whole (an activity that according to this person belongs to the superordinate category "sports"), he or she may become afraid of different types of sports (i.e., exemplars belonging to the category "sports"; e.g. swimming, cycling, running) regardless of their perceptual resemblance to yoga, and as a consequence might cease all sport-related activities.

Research on this conceptual path of fear generalization is scarce, and to our knowledge this question has never been addressed in the field of pain-related fear. Therefore, we sought to investigate (a) acquisition of fear of movement-related pain to physically dissimilar exemplars of one superordinate "action" category (CS+), and (b) fear generalization to novel CS+ exemplars (GSs) belonging to the same conceptual category. We adapted the VJM paradigm using unique exemplars of superordinate action categories (opening/closing boxes) as CSs, and a painful electrocutaneous stimulus as the pain-US. Another set of unique exemplars (boxes with different combinations of color, size, and shape) of both action categories served as GSs. Conditioned pain-related fear was measured through self-reports (pain-related fear and US-expectancy ratings) as well as a psychophysiological index of fear (eyeblink startle response). We hypothesized that (a) at the end of acquisition, fear and US-expectancy ratings as well as the eyeblink startle responses would be higher for the exemplars of the CS+ category than for the exemplars of the CS- category; and (b) during the test of generalization, fear and US-expectancy ratings as well as the eyeblink startle responses would be higher for novel exemplars of the CS+ category (GS+) than for novel exemplars of the CS- category (GS-).

\section{PARTICIPANTS}

\section{Method}

In total, 50 healthy, pain-free individuals (31 women, 19 men) voluntarily participated in this study and received course credit or $€ 12$ (approximately $\$ 13$ ) to compensate them for their time and effort. They were between 18 and 38 years old $(M=23.32, S D=$ 4.32). Participants were recruited using the departmental experiment management system and through word of mouth. Exclusion criteria were pregnancy, cardiovascular diseases, chronic or acute respiratory diseases (e.g., asthma, bronchitis), neurological diseases (e.g., epilepsy), any other severe medical condition, any current or past psychiatric disorders including clinical depression and anxiety disorders, chronic pain, uncorrected hearing problems, painful hand-related problems, the presence of a cardiac pacemaker or any other electronic medical devices, and any condition that might influence the ability to make judgments/give verbal ratings (e.g., cognitive impairment due to stroke or brain injury). All participants completed a checklist to ensure that none of these criteria were applicable. Next, they signed the informed consent form. The experimental protocol was approved by the Social and Societal Ethics Committee of the University of Leuven (registration number G-2015 01 147).

\section{STIMULUS MATERIAL AND MEASURES}

The experiment was run on a Windows XP computer (Dell Optiplex 755) with 2 GB RAM and an Intel Core2 Duo processor at $2.33 \mathrm{GHz}$ and an ATI Radeon 2400 graphics card with $256 \mathrm{MB}$ of video RAM. Stimulus presentation was controlled with the 
free software package Affect 4.0 (Spruyt, Clarysse, Vansteenwegen, Baeyens, \& Hermans, 2010).

CSs consisted of 20 unique exemplars of two functional categories: closing and opening boxes (10 opening boxes, 10 closing boxes). These boxes had different colors, shapes, and sizes to reduce the influence of mere perceptual similarity of the exemplars belonging to the same category. At the beginning of a trial, these boxes were either open or closed. In order to "open" a closed box or to "close" an open box, participants moved a (Logitech Attack 3) joystick into the signaled direction (i.e., to the left or to the right). During this movement, an animation was run showing the actual opening or closing of the box. The GSs were 16 novel and unique exemplars of the two learned functional categories ( 8 opening boxes, 8 closing boxes). Thus, these boxes had different color, shape, and size combinations than those used during the acquisition phase. An electrocutaneous stimulus (2-ms duration) delivered by a commercial constant current stimulator (DS7A, Digitimer, Welwyn Garden City, UK) served as the unconditioned stimulus (pain-US). This stimulation was administered through surface Sensormedics electrodes $(8 \mathrm{~mm})$ filled with K-Y gel that were attached to the wrist of the dominant hand. During the calibration procedure, participants received a series of electrocutaneous stimuli of increasing intensity and were asked to indicate how intense/painful each stimulus was on a scale from 1 to 10 ( 1 = You feel something but this is not painful, it is merely a sensation; $2=$ This sensation starts to be painful, but it is still a very weak pain; $10=$ This is the worst pain you can imagine). Participants were instructed that a subjective stimulus intensity of 8 (Significantly painful and demanding some effort to tolerate) was targeted, but were asked to notify the experimenter when they did not want to receive a stimulus of higher intensity or when they wanted the intensity to be set back to a lower level. Lowering the intensity of the electrocutaneous stimulus was allowed only during the calibration phase; during the actual conditioning procedure, the intensity of the selected pain-US was never adjusted. The mean subjective stimulus intensity was $8.00(S D=0.40$, range $=6-9)$, and the mean physical stimulus intensity was $32.12 \mathrm{~mA}$ $(S D=20.47$, range $=6-100)$.

Conditioned pain-related fear was measured through self-reports as well as a psychophysiological measure of fear learning - that is, the eyeblink startle response. The eyeblink startle response is a component of the reflexive cross-species, full-body defensive response mobilization, which is triggered by startleevoking stimuli (e.g., acoustic startle probe) and can be measured by the tension in the muscles under- neath the eye (Blumenthal et al., 2005; Davis, Walker, Miles, \& Grillon, 2010). Startle modulation refers to the potentiation of the startle reflex during fear states elicited by the anticipation of an aversive stimulus (e.g., an electrocutaneous stimulus); fearpotentiated startle (FPS) has been widely used as a proxy measure of conditioned fear (Grillon, 2002; Lang, Davis, \& Ohman, 2000). In the present setup, the startle probe was a $100 \mathrm{dBA}$ burst of white noise with instantaneous rise time presented binaurally for $50 \mathrm{~ms}$ through headphones (Philips SHP2500). Startle eyeblink responses elicited by startle probes delivered during the CS/GS movements served as an index of cued pain-related fear. Startle eyeblink responses elicited by startle probes during the intertrial interval (ITI) served as an index of contextual pain-related fear (Vansteenwegen, Iberico, Vervliet, Marescau, \& Hermans, 2008). We expected that the ITI startle responses would not be potentiated, because during this period it was safe and no painful electrocutaneous stimulus was anticipated. Therefore, in the present design, the ITI startle responses served as a baseline/control measure of psychophysiological responding.

\section{PROCEDURE}

We adapted the VJM paradigm (Meulders et al., 2011; Meulders \& Vlaeyen, 2013) to study the acquisition and generalization of pain-related fear based on conceptual knowledge. The experiment was conducted during a 90-minute session and consisted of a preparation phase, a practice phase, a startle habituation phase, an acquisition phase, and a generalization test. CSs were unique exemplars of two functional, superordinate categories (opening/ closing boxes). During the acquisition phase, exemplars of the CS+ category were followed by the painUS in $80 \%$ of the trials, and exemplars of the CS- category were never followed by the pain-US. The functional category that served as the CS+ and CSwas counterbalanced across participants. This means that half of the participants received a painful stimulus paired with opening boxes, whereas the other half received a painful stimulus paired with closing boxes. Because the acquisition and generalization (tested under extinction) of category-based pain-related fear was under investigation, we used a partial $(80 \%)$ reinforcement schedule, as it is known to slow down both acquisition (Dunsmoor, Bandettini, \& Knight, 2007; Schurr \& Runquist, 1973) and extinction rates (Haselgrove, Aydin, \& Pearce, 2004; Schurr \& Runquist, 1973). In half of the trials, participants moved the joystick to the left to "open" a closed box (e.g., CS+ category) or to "close" an open box (e.g., CS- category), and in the other half of the trials participants moved the joystick to the right. That way, 
the same movements (i.e., moving the joystick to the left) could lead to different outcomes (opening or closing boxes) and thus served a different purpose. Therefore, participants should learn that it is not the movement direction, the color, the shape, or the size of the boxes that predicts the pain-US but that it is the function of the behavior (i.e., opening or closing boxes) that predicts the pain-US. During the test of generalization, novel exemplars of the same functional categories (GSs) - that is, novel boxes with unique combinations of shape, color, and size other than those used in the acquisition phase-were tested.

\section{Preparation}

Upon arrival to the laboratory, participants were informed that the experiment involved the repeated presentation of electrocutaneous stimuli (pain-US) and short loud noises (acoustic startle probes). Participants were also told that they were free to decline participation at any time without any negative consequences. After providing informed consent, electrodes for eyeblink startle responses and the administration of the electrocutaneous stimulus were attached and the calibration procedure of the pain-US was initiated.

\section{Practice}

Before starting the practice phase, participants received extensive written instructions about the experimental task. These instructions were presented via Affect 4.0 (Spruyt et al., 2010) on the computer screen in front of them. During the practice phase, participants were requested to "open" or "close" boxes by moving the joystick into the direction signaled by a red asterisk (i.e., the direction signal). They could start moving when prompted by a white fixation cross that was presented in the middle of the computer screen (i.e., the starting signal; see Figure 1). In total, 12 trials were run: participants were requested to open six boxes and close six boxes with three joystick movements to the left and three joystick movements to the right in each CS category (opening/closing boxes). The presentation order of the trials was semirandomized with no more than two consecutive trials of the same CS category into the same movement direction.

Each trial consisted of a pre-CS interval of $3 \mathrm{~s}$ and a post-CS interval of $5 \mathrm{~s}$. After the pre-CS interval, an open or closed box was presented in the middle of the screen. Either on the left or right side of the box, the direction signal appeared, indicating the direction of the joystick movement that needed to be performed. After $500 \mathrm{~ms}$, the direction signal disappeared and questions assessing pain-related fear and pain-US expectancy were presented on the screen. Two seconds after answering these questions, the starting signal was presented. Upon presentation of the starting signal, participants were requested to "open" or "close" the presented box by moving the joystick as fast and accurately as possible into the signaled direction. During the movement, an

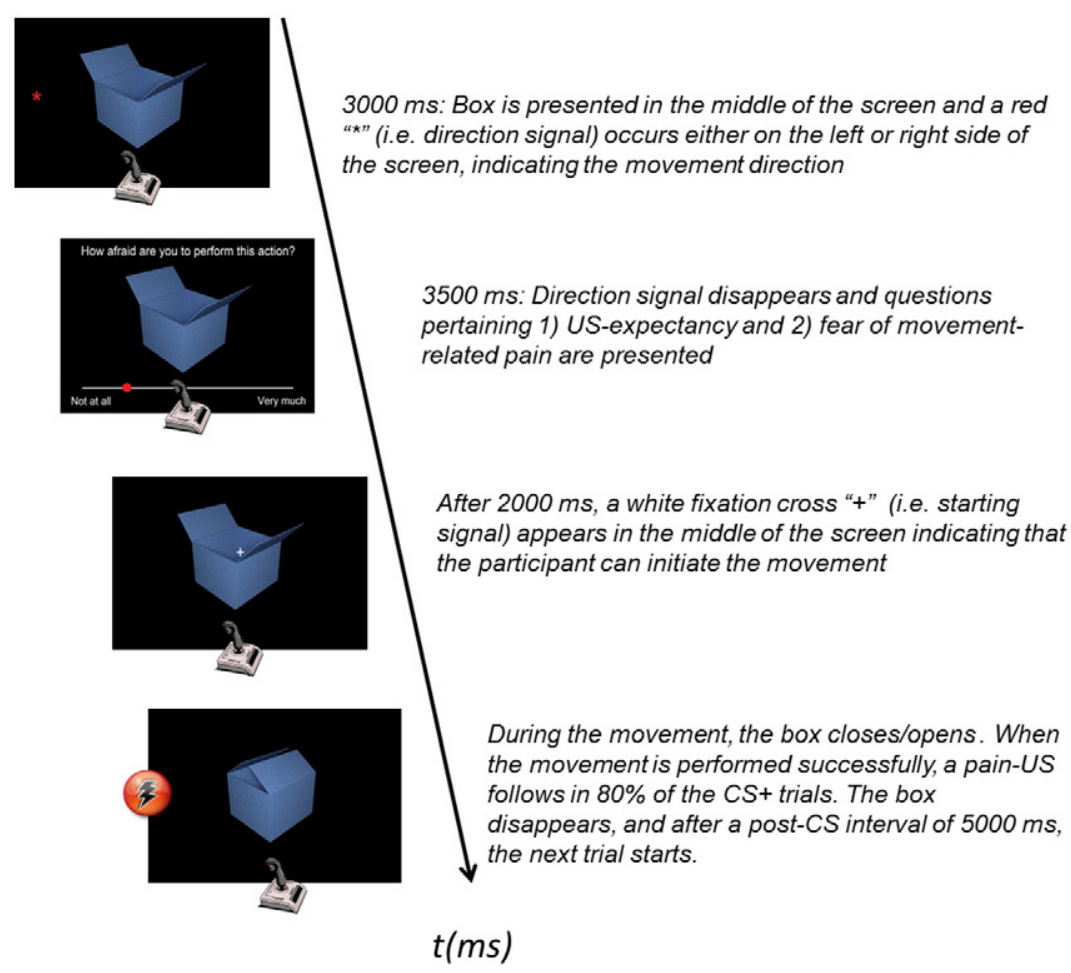

FIGURE I Schematic overview of the experimental task. 
animation of the box closing/opening was shown, and when the movement was successfully completed, the box disappeared from the screen and a post-CS interval of 5 s elapsed before a new trial commenced. When participants moved in the wrong direction, an error message was shown to inform them, and the trial was restarted. During the practice phase, no acoustic startle probes or pain-USs were presented, and the experimenter gave online verbal feedback about the task performance.

\section{Startle Habituation}

Because it is expected that the first responses to startle probes are significantly larger than latter ones, we inserted a startle probe habituation phase to correct for such a possible confound in the data. In other words, initial responses to startle probes are disproportionately high (due to orienting responses and novelty), and decrease quickly (i.e., habituate) following a couple of probe presentations. Because modulation of the response was under investigation, we used the habituated startle response as an onset reference for the measures. This phase consisted of eight trials, each lasting $13 \mathrm{~s}$ (with a variable ITI of on average 2 s). On each trial, one startle probe was presented randomly between 8 and $12 \mathrm{~s}$ after trial onset. During this phase, the lights were dimmed, participants wore headphones, and no pain-USs were delivered.

\section{Acquisition}

This phase was similar to the practice phase, except that pain-USs and startle probes were now presented. Pain-related fear conditioning occurred over four acquisition blocks that each included the same 10 unique exemplars of both CS categories (10 open and 10 closed boxes; 80 trials in total). Again, half of the open boxes were to be closed with joystick movements to the right and the other half with joystick movements to the left, whereas half of the closed boxes were to be opened with joystick movements to the right and the other half with joystick movements to the left. For each participant, one functional category (e.g., closing boxes) was designated the $\mathrm{CS}_{+}$, and $80 \%$ of the exemplars belonging to this category were randomly reinforced with delivery of the pain-US after completing the signaled joystick movement. There was no contingency between the occurrence of the pain-US and the direction of joystick movement. The other functional category (e.g., opening boxes) served as the CS-, and none of the exemplars belonging to this category were reinforced with a pain-US. In $40 \%$ of the trials (i.e., 4 out of 10 exemplars of each CS category in each acquisition block), questions assessing pain-US expectancy and how afraid participants were to perform the movement were presented before they actually carried out the joystick movement. Questions were presented pseudo-randomly with the restriction that left/right joystick movements were equally distributed across CS+ and CS- assessment trials. We used $40 \%$ of assessment trials in order to follow the development of the CR without interfering too much with the conditioning process itself. After each acquisition block, participants also rated the pain-US intensity and unpleasantness and how afraid they were of the "relevant" CS categories (opening/closing boxes) as well as other "irrelevant" perceptual and proprioceptive features: (a) movement direction (left/right), (b) size (small/big boxes), and (c) color (dark-/ightcolored boxes).

Although a CS movement was of variable length depending on participants' movement speed, a trial again included an ITI consisting of a pre-CS interval of $3 \mathrm{~s}$ and a post-CS interval of $5 \mathrm{~s}$. The rest of the timing was the same as during the practice phase. On each trial, one startle probe was presented; within each acquisition block, six exemplars of the CS+ category and six exemplars of the CS- category were probed (for both categories: three during movement to the left, three during movement to the right). These startle probes were presented $200 \mathrm{~ms}$ after participants started "opening" or "closing" the boxes (i.e., when they started to move the joystick). Eight probes were presented during the ITI (four on CS+ trials and four on CS- trials): two probes were presented randomly between 700 and $2200 \mathrm{~ms}$ of the pre-CS interval, and two probes were presented randomly between 2200 and $3700 \mathrm{~ms}$ of the postCS interval. Thus, in each acquisition block, 12 probes were presented during movements and 8 were presented during the ITI (i.e., context alone). Participants were not informed about the contingencies between the functional categories (CSs) and the pain-US.

\section{Test of Generalization}

The procedure for the generalization phase was similar to the acquisition phase. In this phase, we tested 8 novel exemplars of both the CS+ and CScategories (respectively referred to as GS + and GS-; 16 trials in total). These GSs were never followed by the pain-US. To prevent extinction, we also presented two original exemplars of both categories that were used during acquisition (4 trials in total); original exemplars from the CS+ category were reinforced with the pain-US. These 20 trials ( 8 GS +, 8 GS-, 2 $\mathrm{CS}_{+}$, and $2 \mathrm{CS}$-) were run in a random order. There were two important procedural differences with the acquisition phase: (a) on each trial, a startle probe was delivered during the GS (or CS) movement, but never during the ITI; and (b) on each trial, participants rated pain-US expectancy and how 
afraid they were to perform the movement before actually carrying out the joystick movement.

\section{MAIN OUTCOME VARIABLES}

Prospective Fear of Movement-Related Pain Ratings During the practice, acquisition, and generalization phases, participants rated how afraid they were to perform the "signaled" movements (CSs/GSs) before actually doing so. They were asked to rate "How fearful are you to perform this action?" on a 0 (Not fearful at all) to 10 (Very afraid) Likert scale.

\section{Prospective Pain-US Expectancy Ratings}

During the practice, acquisition, and generalization phases, participants rated the extent to which they expected the painful stimulus to occur when performing the "signaled" movements (CSs/GSs) on a 0 (Not at all) to 10 (Very much) Likert scale.

\section{Startle Eyeblink Modulation}

Orbicularis oculi electromyographic (EMG) activity was recorded with three $\mathrm{Ag} / \mathrm{AgCl}$ Sensormedics electrodes $(4 \mathrm{~mm})$ filled with electrolyte gel. After cleaning the skin with exfoliating peeling cream to reduce interelectrode resistance, electrodes were placed on the left side of the face according to the site specifications proposed by Blumenthal et al. (2005). The raw signal was amplified by a Coulbourn isolated bioamplifier with bandpass filter (LabLinc v75-04). The recording bandwidth of the EMG signal was between $90 \mathrm{~Hz}$ and $1 \mathrm{kHz}( \pm 3 \mathrm{~dB})$. The signal was rectified online and smoothed by a Coulbourn multifunction integrator (LabLinc v76-23 A) with a time constant of $20 \mathrm{~ms}$. The EMG signal was digitized at $1,000 \mathrm{~Hz}$ from $200 \mathrm{~ms}$ before the onset of the auditory startle probe until $1000 \mathrm{~ms}$ after probe onset.

\section{MANIPULATION CHECKS}

Retrospective Pain-Related Fear

As a manipulation check, after each conditioning block, we assessed how afraid participants were of the CS categories (opening vs. closing boxes). They answered the following question: "To what extent were you afraid to perform the action of opening/ closing a box during the previous block?" on a Likert scale ranging from 0 (Not afraid at all) to 10 (Very afraid). To ensure that this assessment would not focus participants' attention solely on the functional action categories that were of relevance to predict the pain, they also rated fear related to other perceptual and proprioceptive features that varied among the different exemplars of the functional categories but were not relevant to predict the pain: (a) movement direction, (b) size, and (c) color. Respectively, they answered the following questions on a Likert scale from 0 (Not afraid at all) to 10 (Very afraid): "To what extent were you afraid to perform the movement to the left/right during the previous block?"; "To what extent were you afraid of large/small boxes during the previous block?"; and "To what extent were you afraid of light/dark colored boxes during the previous block?"

\section{Pain-US Intensity and Unpleasantness}

After each conditioning block, participants answered the questions "How painful did you find the electrocutaneous stimulus in the previous block?" and "How unpleasant did you find the electrocutaneous stimulus in the previous block?" on 0 (Not at all) to 10 (Very much) Likert scales to monitor possible habituation or sensitization effects.

\section{EXPERIMENTAL SETTING}

Participants were seated in an armchair (0.6-meter screen distance) in a sound-attenuated and dimmed experimental room, adjacent to the experimenter's room. Further verbal communication was possible through an intercom system; the experimenter observed the participants and their physiological responses online by means of a closed-circuit TV installation and computer monitors.

\section{RESPONSE DEFINITION AND DATA ANALYSIS OVERVIEW}

Response Definition of the Startle Modulation

Using PSPHA (Declercq, De Houwer, \& Baeyens, 2008), a modular script-based program, we calculated the peak amplitudes defined as the maximum of the response curve within $21-175 \mathrm{~ms}$ after the startle probe onset. All startle waveforms were visually inspected off-line, and technical abnormalities and artifacts were eliminated using the PSPHA software. Every peak amplitude was scored by subtracting its baseline score (averaged EMG level between 1 and $20 \mathrm{~ms}$ after the probe onset). The raw scores were transformed to $z$ scores to account for interindividual differences in physiological reactivity. In order to optimize the visualization of the startle data and avoid negative values on the $y$-axis, $T$ scores-a linear transformation of the $z$ scores-were used in the figures. Averages were calculated for responding during movements of CS/GS exemplars of both functional categories and ITI separately.

\section{Data Analysis Overview}

We carried out separate repeated measures (RM) ANOVAs on the respective dependent measures to examine the acquisition and generalization of painrelated fear based on conceptual knowledge. In particular, we hypothesized that (a) at the end of acquisition (ACQ4), fear and US-expectancy ratings 
as well as the eyeblink startle responses would be higher for the exemplars of the CS+ category than for the exemplars of the CS- category; and (b) during the test of generalization, fear and US-expectancy ratings as well as the eyeblink startle responses would be higher for novel exemplars of the CS+ category (GS +) than for novel exemplars of the CS- category (GS-). The $\alpha$ level was set at .05. In testing our a priori hypotheses, a Bonferroni correction was applied when using multiple planned comparisons. Greenhouse-Geisser corrections are reported when appropriate. Uncorrected degrees of freedom and corrected $p$ values are reported together with $\varepsilon$ and the effect size indication $\eta_{p}^{2}$ is reported for significant ANOVA effects and Cohen's $d$ for planned comparisons. The interpretation thresholds based on Cohen (1988) and extended by Rosenthal (1996) can be summarized as follows: $.20=$ small, $.50=$ medium, $.80=$ large , and $1.30=$ very large. Statistical analyses for all dependent measures were run with Statistica 12 software.

\section{Results \\ PROSPECTIVE FEAR OF MOVEMENT-RELATED PAIN RATINGS \\ Practice}

We conducted a paired samples $t$ test on the mean pain-related fear ratings for the CS+ and CScategories during the practice phase. As expected, before conditioning, fear ratings were low and did not differ between the CS+ and CS- categories, $t(49)=$ $1.59, p=.12$ (see Figure 2).

\section{Acquisition}

We carried out a 2 (Stimulus Category: CS+, CS-) $\times 4$ (Block: ACQ1, ACQ2, ACQ3, ACQ4) RM ANOVA on the mean pain-related fear ratings for the CS categories during the four acquisition blocks (see Figure 2). There was a significant main effect of Stimulus Category, $F(1,49)=39.04$, $p<.0001, \eta_{p}^{2}=.44$, and a significant main effect of Block, $F(3,147)=30.22, p<.0001, \varepsilon=.67, \eta_{p}^{2}=$ .38 , both of which were qualified by a Stimulus Category $\times$ Block interaction, $F(3,147)=36.99$, $p<.0001, \varepsilon=.84, \eta_{p}^{2}=.43$. Planned comparisons confirmed that at the end of the acquisition phase (ACQ4), the exemplars of the CS+ category elicited more pain-related fear than did those of the CScategory, $F(1,49)=54.91, p<.0001, d=1.04$, although this was not the case in the beginning of the acquisition phase (ACQ1), $F<1$.

\section{Test of Generalization}

To examine generalization of pain-related fear to the novel exemplars (GSs) of the learned CS categories, we ran an RM ANOVA (Stimulus Category: CS+, GS +, GS-, CS-; see Figure 2). There was a significant effect of Stimulus Category, $F(3,147)=38.83, \varepsilon=$ $.41, p<.0001, \eta_{p}^{2}=.44$. Planned comparisons confirmed that the original exemplars of the CS+ category still elicited more pain-related fear than did the original exemplars of the CS- category, $F(1,49)=$ $36.45, p<.0001, d=.77$, suggesting that no extinction took place during the generalization test. More importantly and in line with our expectations,

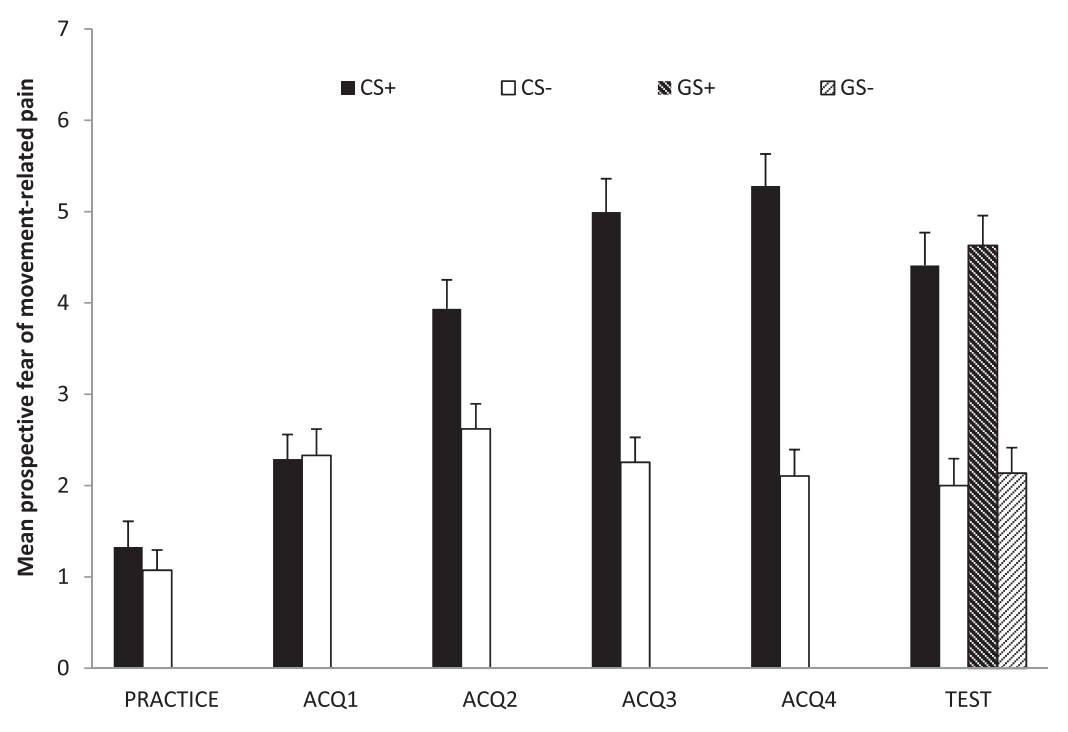

FIGURE 2 Mean prospective self-reported fear of movement-related pain ( \pm SEs) in response to the CS+/CS- exemplars during practice (PRACTICE) and acquisition (ACQI-4), and in response to the GS+/GS-/CS+/CS- exemplars during the generalization test (TEST). 
participants reported more pain-related fear in response to the novel exemplars of the CS+ category (GS+) as compared with novel exemplars of the CScategory (GS-), $F(1,49)=46.91, p<.0001, d=.86$. No such differences occurred between the CS+ and the GS + exemplars, $F(1,49)=2.60, p=.11, d=$ .07 , or the CS- and the GS- exemplars, $F(1,49)=$ $1.36, p=.25, d=.05$, suggesting that there was a perfect transfer of the learned contingencies based on a certain set of exemplars to novel exemplars of the same functional category.

\section{PROSPECTIVE PAIN-US EXPECTANCY RATINGS \\ Practice}

We conducted a paired samples $t$ test on the mean pain-US expectancy ratings for the CS+ and CScategories during the practice phase. As expected, before conditioning, pain-US expectancy ratings were low and did not differ between the CS+ and CS- categories, $t(49)=0.41, p=.68$ (see Figure 3$)$.

\section{Acquisition}

We carried out a 2 (Stimulus Category: CS+, CS-) $\times 4$ (Block: ACQ1, ACQ2, ACQ3, ACQ4) RM ANOVA on the mean pain-US expectancy ratings for the CS categories during the four acquisition blocks (see Figure 3). There was a significant main effect of Stimulus Category, $F(1,49)=62.02$, $p<.0001, \eta_{p}^{2}=.56$, but not of Block $(F<1)$. This was qualified by a significant Stimulus Category $x$ Block interaction, $F(3,147)=45.80, p<.0001, \varepsilon=$ $.84, \eta_{p}^{2}=.48$. Planned comparisons confirmed that at the end of the acquisition phase (ACQ4), the CS+ category induced higher pain-US expectancies than did the CS- category, $F(1,49)=78.91, p<.0001$, $d=1.59$, although this was not the case in the beginning of the acquisition phase (ACQ1), $F<1$.

\section{Test of Generalization}

To examine generalization of pain-US expectancy to the novel exemplars (GSs) of the learned CS categories, we ran a RM ANOVA (Stimulus Category: CS+, GS +, GS-, CS-) (see Figure 3). There was a significant effect of Stimulus Category, $F(3$, $147)=42.47, \varepsilon=.47, p<.0001, \eta_{p}^{2}=.46$. Planned comparisons confirmed that participants still expected the pain-US to occur more after the original exemplars of the CS+ category than the original exemplars of the CS- category, $F(1,49)=32.35, p<.0001, d=.88$. More importantly and in line with the pain-related fear ratings, participants showed higher pain-US expectancies in response to the novel exemplars of the CS+ category $(\mathrm{GS}+)$ as compared with novel exemplars of the CS- category (GS-), $F(1,49)=66.74$, $p<.0001, d=1.25$. No such differences occurred between the CS+ and the GS + exemplars, $F(1,49)=$ $2.91, p=.09, d=.13$, or the CS- and the GSexemplars, $F<1$.

\section{STARTLE EYEBLINK MODULATION \\ Acquisition}

We carried out a 3 (Stimulus Type: CS+, CS-, ITI) $\times 4$ (Block: ACQ1, ACQ2, ACQ3, ACQ4) RM ANOVA on the mean startle amplitudes of the CS+ and CScategories as well as the ITI during the acquisition phase (see Figure 4). This analysis yielded a significant

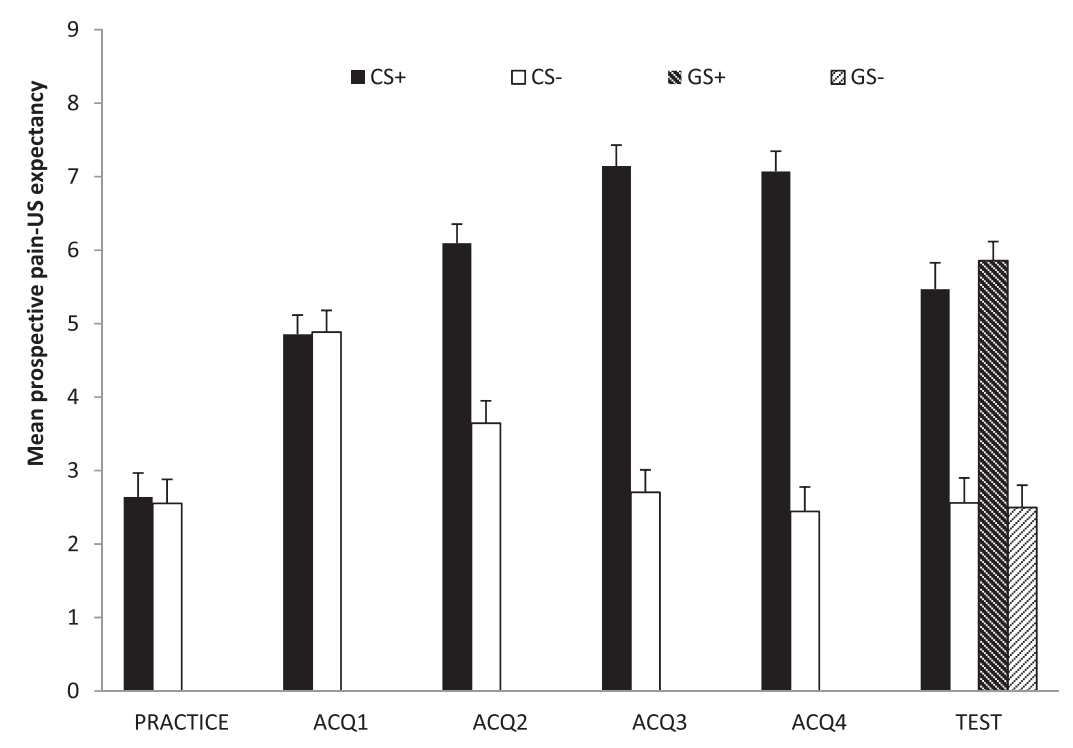

FIGURE 3 Mean prospective pain-US expectancy $( \pm$ SEs) in response to the $\mathrm{CS}+1$ CS- exemplars during practice (PRACTICE) and acquisition (ACQI-4), and in response to the GS+/GS-/CS+/CS- exemplars during the generalization test (TEST). 


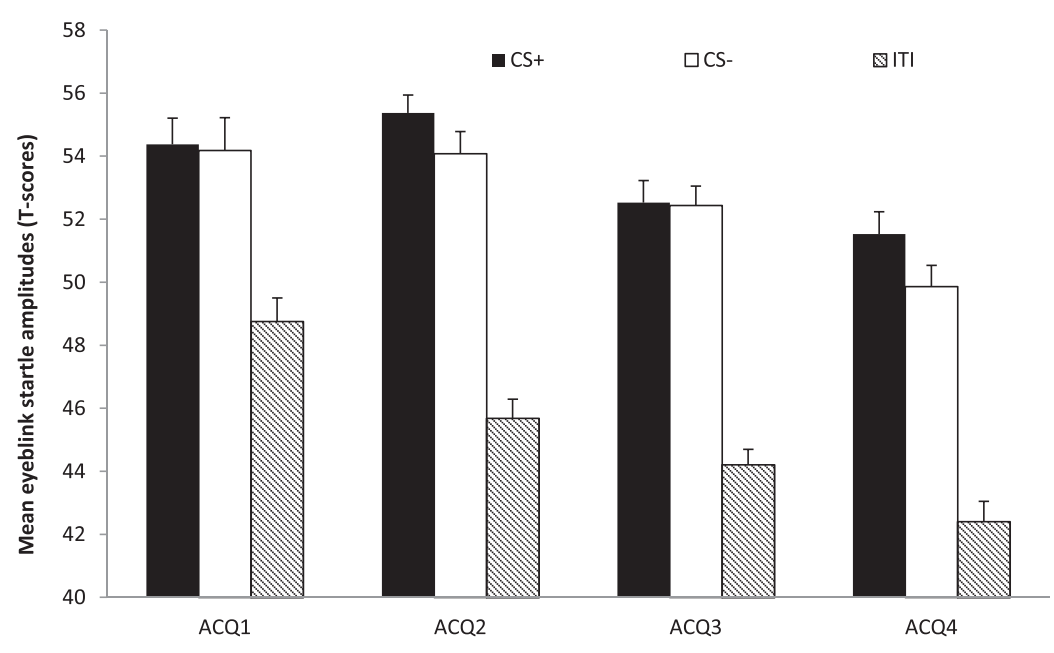

FIGURE 4 Mean startle eyeblink amplitudes ( \pm SEs) during the CS +/CS- exemplars and the ITI during acquisition (AI-4). Note. For graphic purposes, $T$ scores were used.

main effect of Block, $F(3,147)=19.74, \varepsilon=.58$, $p<.0001, \eta_{p}^{2}=.29$, and a significant main effect of Stimulus Type, $F(2,98)=76.93, \varepsilon=.81, p<.0001$, $\eta_{p}^{2}=.61$, both of which were qualified by a Stimulus Type $\times$ Block interaction, $F(6,294)=3.32, \varepsilon=.77$, $p<.01, \eta_{p}^{2}=.06$. Although startle amplitudes during the exemplars of the CS+ category tended to be elevated compared with those of the CS- category, planned comparisons did not support statistical significance, $F(1,49)=3.25, p=.08, d=.25$. Interestingly, startle amplitudes during both CS categories were significantly higher than during the ITI, $F(1$, 49) $=105.66, p<.0001, d=1.11$, suggesting that both CS categories showed elevated psychophysiological responding as compared with the safe context.

Test of Generalization

Because there were no reliable acquisition effects in the startle eyeblink measures, generalization effects were not further reported.

\section{MANIPULATION CHECKS}

\section{Retrospective Pain-Related Fear}

To ensure that the other irrelevant features of the exemplars of the CS+ category elicited less fear than did the relevant feature (i.e., the function of opening/ closing a box), we conducted a 5 (Block: ACQ1, ACQ2, ACQ3, ACQ4, Test) $\times 8$ (Stimulus Category: CS+, CS-, left, right, dark, light, big, small) RM ANOVA on retrospective pain-related fear ratings (see Figure 5). This analysis showed a significant main effect of Block, $F(4,196)=7.05, \varepsilon=.52$, $p<.0001, \eta_{p}^{2}=.13$, and a significant main effect of Stimulus Category, $F(7,343)=32.07, \varepsilon=.57$, $p<.0001, \eta_{p}^{2}=.40$, both of which were qualified by a Stimulus Category $\times$ Block interaction, $F(28$, $1,372)=4.36, \varepsilon=.47, p<.0001, \eta_{p}^{2}=.08$.
Planned comparisons revealed that the pain-related fear ratings for the $\mathrm{CS}+$ category were higher than for the CS- category, $F(1,49)=96.28, p<.0001, d=$ 1.10. In addition, fear elicited by the CS+ category was significantly higher than for other features on which the exemplars within categories could vary but were shared among categories, such as brightness of the boxes (dark colored vs. light colored), movement direction (moving to the left vs. moving to the right), and the size of the boxes (big vs. small), $F(1,49)=$ $62.79, p<.0001, d=.60$. The opposite pattern was observed for the CS- category-that is, other features on which the exemplars within categories could vary but were shared among categories elicited significantly more pain-related fear than did the CS- category, $F(1,49)=45.31, p<.0001, d=.53$.

\section{Pain-US Intensity and Unpleasantness}

To ensure that the pain-US remained significantly painful during the entire conditioning procedure (and did not habituate excessively), we conducted a 2 (Rating: intensity, unpleasantness) $\times 5$ (Block: ACQ1, ACQ2, ACQ3, ACQ4, Test) RM ANOVA on mean retrospective pain-US intensity and unpleasantness ratings (see Figure 6). This analysis yielded a significant main effect of Block, $F(4$, 196) $=9.58, \varepsilon=.80, p<.0001, \eta_{p}^{2}=.16$, suggesting that over time, ratings of both unpleasantness and intensity changed. There was also a significant main effect of Rating, $F(1,49)=39.11, p<.0001, \eta_{p}^{2}=$ .44 , indicating that unpleasantness ratings were higher than pain-US intensity ratings. The Rating $\times$ Block interaction was not significant, $F(4,196)=$ $1.66, \varepsilon=.80, p=.17, \eta_{p}^{2}=.03$, suggesting that the pain-US intensity and unpleasantness ratings demonstrated a similar pattern of change. In particular, there was a slight increase in pain-US intensity (linear trend: 


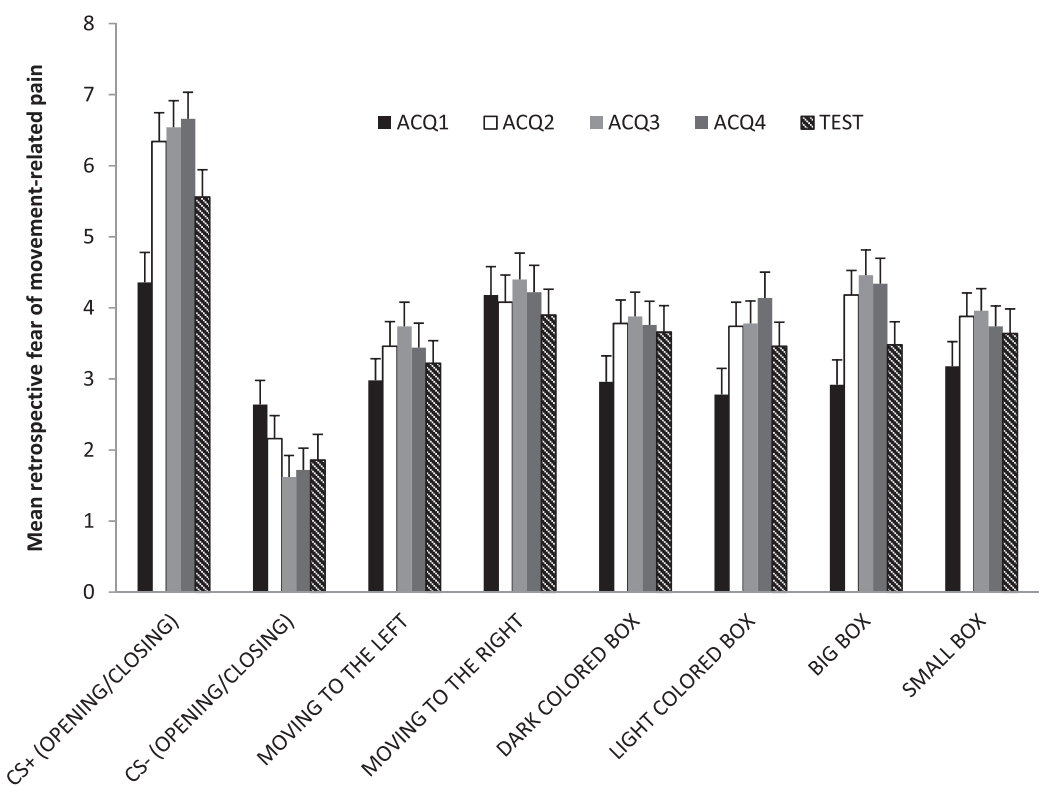

FIGURE 5 Mean retrospective pain-related fear ( \pm SEs) in response to relevant (i.e., action category: opening vs. closing boxes) and irrelevant category features (i.e., movement direction: moving to the left vs. right; box brightness: dark-colored vs. light-colored boxes; size: big vs. small boxes).

$F(1,49)=17.31, p<.001)$, and unpleasantness (linear trend: $F(1,49)=10.11, p<.01$ ) across blocks, suggesting that there was some pain sensitization. During the test of generalization, the pain-US intensity, $F(1,49)=13.07, p<.001, d=.15$, and unpleasantness, $F(1,49)=22.60, p<.0001, d=$ .29 , ratings decreased significantly, likely due to reduced reinforcement rate during this phase.

\section{Discussion}

Previous research has shown that perceptual/ proprioceptive similarity with a movement that featured in a painful episode facilitates the generalization of conditioned pain-related fear to novel

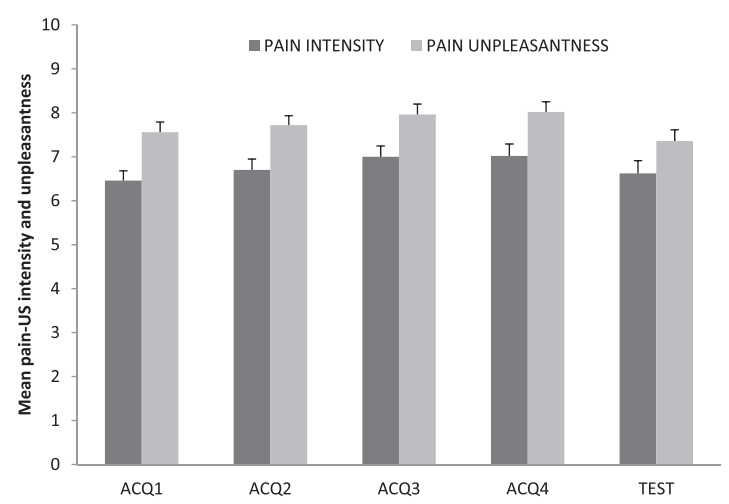

FIGURE 6 Mean pain-US intensity and unpleasantness ( \pm SEs) during acquisition ( $\mathrm{AQCl}-4)$ and the generalization test (TEST). movements (Meulders et al., 2013; Meulders \& Vlaeyen, 2013). This type of fear generalization has been referred to as perceptual pain-related fear generalization. A hallmark of human cognition is the ability to additionally extract conceptual knowledge from a learning episode; however, research on this conceptual pathway to fear generalization is scant. The aim of the current study was to investigate the acquisition and generalization of pain-related fear based on conceptual knowledge relating to category membership.

First, we successfully established the acquisition of fear of movement-related pain based on a superordinate "action" category membership. In particular, participants learned that unique exemplars of one action category ( $\mathrm{CS}+$; e.g., opening boxes) predicted a painful electrocutaneous stimulus (pain-US), whereas unique exemplars of another action category (CS-; e.g., closing boxes) did not. This pattern was observed in self-reported fear of movement-related pain, as well as in the pain-US expectancy ratings. In contrast, eyeblink startle responses were not elevated in response to the exemplars of the CS+ category as compared with those of the CS- category, but exemplars of both CS+ and CS- action categories elicited higher startle responses than did the context alone (i.e., ITI startle responses).

Second, we demonstrated the spreading of conditioned responding to novel exemplars of the learned CS+ category, but not to the CS- category. 
Participants not only reported more pain-related fear in response to the novel exemplars of the CS+ category $(\mathrm{GS}+$ ) as compared with novel exemplars of the CS- category (GS-), but also showed higher pain-US expectancies to the GS + than to the GS-. In other words, participants reported being more afraid and expected the pain to occur more when they had to open novel boxes (with different combinations of size, color, and shape than the original boxes that were used during acquisition) as compared with when they had to close novel boxes, or vice versa depending on which action (opening/closing boxes) was paired with pain during acquisition. Because there was no reliable acquisition effect in the startle eyeblink measures, no proper test of generalization could be performed. This is in contrast with an earlier study on perceptual pain-related fear generalization by Meulders et al. (2013), who showed a perceptual generalization gradient in the startle eyeblink measures, but failed to observe a similar gradient in the self-reported fear measures. This discrepancy might be explained by several methodological differences between the current study and that of Meulders et al. (2013): (a) Meulders et al. (2013) tested generalization under extinction (i.e., original CSs were not reinforced), which typically leads to quick decline of fear responding; (b) because self-reported fear was not assessed prospectively but in retrospect, fear of movement-related pain might have already extinguished; and (c) because startle eyeblink measures were collected during the generalization trials, they were less affected by extinction (especially in the first trials). Closely related to the current findings, previous research by Bennett, Meulders, Baeyens, and Vlaeyen (2015) has shown that neutral movements' conceptual relationship with pain-associated stimuli can precipitate fear of movement-related pain. In their experiment, two artificial categories were created so that neutral joystick arm movements and nonsense words were equivalent. During the subsequent pain-related fear conditioning procedure, nonsense words of one category were paired with a pain-US $(\mathrm{B}+)$, whereas nonsense words from another category were followed by no pain-US (B-). During the symbolic generalization test, participants were asked to perform specific joystick movements that were trained to be either conceptually similar $(\mathrm{C}+)$ or dissimilar (C-) to the pain-associated nonsense words. Results showed that conceptual equivalence between neutral movements and pain-associated nonsense words $(\mathrm{C}+)$ evoked elevated pain-related fear, pain-US expectancy, and unpleasantness compared with movements conceptually related to nonsense words that were not associated with pain (C-). Like the novel exemplars of the CS+ category in the current study, the movements themselves were never paired with a pain-US, nor were the movements in any sense perceptually similar to the painassociated nonsense words. The present findings further corroborate the idea that category membership based on derived equivalence can facilitate the spreading of pain-related fear.

Some remarkable findings deserve further attention. First, we observed a discrepancy between the self-reported and psychophysiological fear measures. Dissociations between response systems have been reported before (Soeter \& Kindt, 2010) and do not necessarily reflect a failure to replicate. It has been argued that dissociations between declarative knowledge (CS-US contingency awareness) and the psychophysiological fear response might also pertain to relevant information, as both measures might tap into different aspects of fear (fear is associated with both expectancy of harm and elevated psychophysiological arousal; Lang, Bradley, \& Cuthbert, 1998). For example, due to its salience, visual information is often prioritized and captures attention more quickly than other sensory information (tactile, auditory, or proprioceptive information). Because other "irrelevant," mostly visual features such as the size, color, and shape of the boxes, as well as the direction in which participants had to move the joystick, overlapped between CS+ and CS- categories, a possible explanation may be that these features are processed earlier than the relevant "superordinate" action category information. Consequently, these stimulus features might elicit a certain level of fearful arousal leading to nondifferential facilitation of startle responses during exemplars of both CS+ and CS- categories compared with ITI startle responses (i.e., contextual fear). Partial evidence supporting this post hoc explanation is found in the retrospective pain-related fear ratings showing that next to the expected action category-based differential fear learning (e.g., opening vs. closing boxes), the irrelevant categories such as movement direction, size, and color brightness of the boxes generated fear reports situated between the CS+ and CS- categories responses.

Another explanation might be that extracting conceptual information (i.e., categorizing novel exemplars) is a cognitively demanding task. Previous studies have reported that cognitive load can inhibit the startle response (Acocella \& Blumenthal, 1990; Filion, Dawson, \& Schell, 1993; Schell, Wynn, Dawson, Sinaii, \& Niebala, 2000), yet the observed data pattern does not seem to support this explanation because startle responses to both $\mathrm{CS}_{+}$and CS- categories were enhanced compared with ITI startle responses. Alternatively, it seems feasible that information mediated by higher-order cognition such as category information also requires more 
time and effort to process, which in turn raises the possibility that short-latency reflexes such as the eyeblink startle response may not be inhibited by safety cues or facilitated by danger signals based on effortful categorization. On a related note, it is also possible that the startle probes were presented too early after action onset for participants to classify the action as belonging to the CS+ or CS- categories and to produce startle modulation effects. To our knowledge, this is the first study employing startle eyeblink measures in the context of category-based fear conditioning. In fact, at least three important features differ between our study and that of Dunsmoor et al. (2012): CS modality, CS duration, and the type of psychophysiological measure used. In Dunsmoor et al. (2012), visual stimuli presented for 6 seconds served as CSs, and skin conductance responding (SCR) was used as a psychophysiological index of category-based fear learning. The SCR is a longer-latency autonomic response typically emerging around 1 second after stimulus onset and peaking a maximum of 5 seconds later (for visual stimuli), whereas the startle response typically starts 20-50 ms after the startle-eliciting stimulus. This means that the longer stimulus duration (which was possible due to the different modality-i.e., visual stimuli) might have allowed participants to categorize the stimuli on time to generate category-specific anticipatory SCRs. To settle these unresolved issues regarding the observed discrepancy between selfreports and psychophysiological measures, future research may include SCR measures, postpone the presentation of the startle probe after action onset, and preclude the overlap of irrelevant features such as size, shape, and color of the boxes in the CS+ and CS- categories in order to create mutual exclusivity.

Second, compared with previous studies investigating fear of movement-related pain using the VJM paradigm (Meulders et al., 2011; Meulders \& Vlaeyen, 2013), differential category-based fear of movement-related pain took longer to develop. Acquisition may have been slowed down because participants had to extract the relevant information relating to the occurrence of the pain-US for each single exemplar and then had to create categories based on this abstract knowledge; in that sense, acquisition already involved a kind of generalization from each single exemplar to the category. We also found that, once acquired, category-based fear of movement-related pain transferred rigorously to novel exemplars of the CS+ category, although these generalization stimuli were tested under extinction (i.e., GSs were never reinforced, two out of four of the original CS+ exemplars were reinforced). Compared with previous studies investigating the extinction of fear of movement-related pain using the VJM paradigm (Meulders \& Vlaeyen, 2012), extinction learning appears to be slowed down as well. Further research should include more extinction trials to define the boundaries for category-based pain-related fear extinction.

Some limitations of our study should be addressed. First, for practical reasons, we chose to use overlapping exemplar features (e.g., size, color, shape, movement direction) in both of the CS categories. This might have caused the nondifferential elevation of startle responses. Future research should attempt to disentangle whether there is a genuine discrepancy between self-reports and startle responses or whether this is an artifact of the present procedure. Second, in contrast with Dunsmoor et al. (2012), and also for practical reasons, we presented the same exemplars in each conditioning block during acquisition. Therefore, it is possible that acquisition would be even more slowed down when unique exemplars were presented during each acquisition block. Third, there might be a minimal perceptual similarity between the different exemplars of "opening boxes" and "closing boxes" because for each exemplar in the closing boxes category, there was a lid that was sticking out (although the position, shape, size, and angle differed), whereas for the opening boxes category the lid was not visible (i.e., closed box; see Appendix 1). Future research may employ more distinct exemplars of the action categories in order to minimize this low-level perceptual overlap. For example, GSs such as closing/opening doors or jars may be a good method to take the test of category-based generalization a step further. ${ }^{1}$ Fourth, to study the basic learning mechanisms involved in category-based pain-related fear generalization in the lab, we used a sample of relatively young healthy subjects without any psychiatric disorders or medical illnesses. Given that comorbid anxiety, depression, and other medical illnesses are common in people with chronic pain, these learning processes might play out differently in clinical samples. Therefore, future research is needed to validate these findings in chronic pain populations. Finally, our main findings in the self-reported fear and US-expectancy were not replicated in the eyeblink startle measures. Cognitive models of anxiety propose that (conditioned) fear is closely

\footnotetext{
${ }^{1}$ On a related note, in the study of Dunsmoor et al. (2012), the influence of perceptual features also could not be fully ruled out. In their study, unique exemplars of the superordinate category "animals" served as the CS+ and exemplars of the superordinate category "tools" served as the CS-, or vice versa. It can be argued that pictures of tools typically comprise more straight lines than pictures of animals, which might render the exemplars within one category also perceptually more similar.
} 
related to the formation of threat beliefs and harm expectation (Chan \& Lovibond, 1996). Yet, some researchers have argued that verbal measures such as US-expectancy lack objectivity, as they may be susceptible to effects of social desirability and experimental demand (Craske, Hermans, \& Vansteenwegen, 2006). However, it has been argued that (a) US-expectancy measures have face validity, construct validity, predictive validity, and diagnostic validity with respect to anxiety-related disorders (Boddez, Baeyens, Luyten, et al., 2013a); (b) in ambiguous and complex fear-conditioning procedures such as this one, demand effects are not a large concern because the desired responses and study hypotheses are not obvious (Boddez, Baeyens, Hermans, \& Beckers, 2013b); (c) such complex designs may not yield differential effects on psychophysiological indices because these measures are not always sufficiently sensitive to detect subtle differences in modulation between multiple stimuli (Ahmed \& Lovibond, 2015); and (d) modulation of the startle eyeblink is not a unique measure for fear, as sometimes claimed. For example, it is also modulated by attention (Lipp, Cox, \& Siddle, 2001), which might have been an issue in the current study because unique exemplars of the CS categories were used within each block. As a consequence, the orienting response toward all relatively new stimuli might explain the nondifferential potentiation of the startle response.

We have argued that fear learning and generalization is adaptive to a certain degree. The crucial difference between adaptive fear and pathological fear is often conceptualized in terms of fear intensity and avoidance behavior (Dymond et al., 2015). In the case of chronic musculoskeletal pain, fear of movement-related pain becomes pathological to the extent that it impairs normal functioning and prompts avoidance of such movements. Although intensity and avoidance are important in the transition from adaptive to maladaptive fear, we believe that fear overgeneralization, or the spreading of fear to technically safe movements, may be of particular relevance. Although surprisingly few studies addressed fear generalization in the field of pain-related fear, some findings may be of clinical importance.

First and most importantly, treatments that target pain-related fear in chronic pain (e.g., exposurebased therapy) require an in-depth appraisal of the crucial stimuli and their learning history (den Hollander et al., 2016; Vlaeyen, de Jong, Geilen, Heuts, \& van Breukelen, 2001). An important conclusion from generalization research is that fear can be triggered by stimuli that never featured in a pain episode. The present study indeed shows that fear can be evoked by stimuli that are perceptually not related to the original CSs and that were never associated with pain themselves. Therefore, the notion of conceptual fear generalization might shed light on the fact that conditioning experiences are often difficult to reconstruct in a clinical context (Poulton \& Menzies, 2002). However, a more comprehensive understanding of nonperceptual fear generalization is needed before clear recommendations can be given about how these learning processes may impact the conventional treatment approach.

Second, given that generalization may be crucial in the transition from normal to pathological fear, it might be targeted in the prevention of chronic pain disability. For example, discrimination training before a painful medical procedure may be a promising pathway to prevent the spreading of fear from movements and situations that should be avoided to other perceptually or conceptually related events that do not need to be feared or avoided (see Vervliet, Kindt, Vansteenwegen, \& Hermans, 2010, for a similar argument).

To conclude, we demonstrated that pain-related fear can be acquired based on conceptual knowledge, and that this concept-based fear of movement-related pain generalizes to novel exemplars of the CS+ category but not to those of the CS- category. We believe that these novel developments in fear generalization research focusing on the integration with higher-order reasoning and conceptual knowledge are crucial to capture the interplay of pathways involved in the spreading of fear and avoidance behavior in chronic pain conditions.

Supplementary data to this article can be found online at http://dx.doi.org/10.1016/j.beth.2016.11. 014.

\section{Role of the Funding Source}

Ann Meulders is a postdoctoral researcher of the Research Foundation-Flanders (FWO-Vlaanderen), Belgium, (12E3714N). This study was also supported by the Odysseus Grant "The Psychology of Pain and Disability Research Program" to Johan W. S. Vlaeyen and funded by the Research Foundation-Flanders (FWO-Vlaanderen), Belgium, (G090208N), and an EFIC-Grünenthal Research Grant (E-G-G2012: 169518451) to Ann Meulders. Johan W. S. Vlaeyen is currently supported by the "Asthenes" long-term structural funding-Methusalem grant by the Flemish government, Belgium. The Research FoundationFlanders, Grünenthal, and the Flemish government did not have a role in the study design, data collection, analysis or interpretation of the data, writing of the manuscript, or decision to submit the paper for publication. The data of this study were presented in the symposium on New Findings in Clinical Pain Research: Results of the EFIC-Grünenthal Grants 2012 at the Ninth EFIC Congress, Pain in Europe IX, Vienna, Austria, September 2015.

\section{Conflict of Interest Statement}

The authors declare that there are no conflicts of interest. 


\section{References}

Acocella, C. M., \& Blumenthal, T. D. (1990). Directed attention influences the modification of the startle reflex probability. Psychological Reports, 66(1), 275-285. http://dx.doi.org/10. 2466/pr0.1990.66.1.275

Ahmed, O., \& Lovibond, P. F. (2015). The impact of previously learned feature-relevance on generalisation of conditioned fear in humans. Journal of Behavior Therapy and Experimental Psychiatry, 46, 59-65. http://dx.doi.org/10.1016/j.jbtep. 2014.08.001

Bennett, M. P., Meulders, A., Baeyens, F., \& Vlaeyen, J. W. (2015). Words putting pain in motion: The generalization of pain-related fear within an artificial stimulus category. Frontiers in Psychology, 6, 520. http://dx.doi.org/10.3389/fpsyg.2015. 00520

Blumenthal, T. D., Cuthbert, B. N., Filion, D. L., Hackley, S., Lipp, O. V., \& Van Boxtel, A. (2005). Committee report: Guidelines for human startle eyeblink electromyographic studies. Psychophysiology, 42(1), 1-15. http://dx.doi.org/10. 1111/j.1469-8986.2005.00271.x

Boddez, Y., Baeyens, F., Hermans, D., \& Beckers, T. (2013). Reappraisal of threat value: Loss of blocking in human aversive conditioning. Spanish Journal of Psychology, 16, E84. http://dx.doi.org/10.1017/sjp.2013.84

Boddez, Y., Baeyens, F., Luyten, L., Vansteenwegen, D., Hermans, D., \& Beckers, T. (2013). Rating data are underrated: Validity of US-expectancy in human fear conditioning. Journal of Behavior Therapy and Experimental Psychiatry, 44(2), 201-206. http://dx.doi.org/10.1016/j. jbtep.2012.08.003

Chan, C. K., \& Lovibond, P. F. (1996). Expectancy bias in trait anxiety. Journal of Abnormal Psychology, 105(4), 637-647. http://dx.doi.org/10.1037/0021-843X.105.4.637

Cohen, J. (1988). Statistical power analysis for the behavioral sciences (2nd ed.). Hillsdale, NJ: Erlbaum.

Craske, M. G., Hermans, D., \& Vansteenwegen, D. (2006). Fear and learning: From basic processes to clinical implications. Washington, DC: American Psychological Association.

Davis, M., Walker, D. L., Miles, L., \& Grillon, C. (2010). Phasic vs sustained fear in rats and humans: Role of the extended amygdala in fear vs anxiety. Neuropsychopharmacology, 35(1), 105-135. http://dx.doi.org/10.1038/npp.2009.109

Declercq, M., De Houwer, J., \& Baeyens, F. (2008). Evidence for an expectancy-based theory of avoidance behaviour. Quarterly Journal of Experimental Psychology, 61(12), 1803-1812. http://dx.doi.org/10.1080/17470210701851214

den Hollander, M., Goossens, M., de Jong, J., Ruijgrok, J., Oosterhof, J., Onghena, P., ... Vlaeyen, J. W. (2016). Expose or protect? A randomized controlled trial of exposure in vivo vs pain-contingent treatment as usual in patients with complex regional pain syndrome type 1. Pain, 157(10), 2318-2329.

Dunsmoor, J. E., Bandettini, P. A., \& Knight, D. C. (2007). Impact of continuous versus intermittent CS-UCS pairing on human brain activation during Pavlovian fear conditioning. Behavioral Neuroscience, 121(4), 635-642. doi:200711112-001 [pii]10.1037/0735-7044.121.4.635

Dunsmoor, J. E., Kragel, P. A., Martin, A., \& LaBar, K. S. (2013). Aversive learning modulates cortical representations of object categories. Cerebral Cortex. http://dx.doi.org/10. 1093/cercor/bht138

Dunsmoor, J. E., Martin, A., \& LaBar, K. S. (2012). Role of conceptual knowledge in learning and retention of conditioned fear. Biological Psychology, 89(2), 300-305. http://dx.doi.org/10.1016/j.biopsycho.2011.11.002
Dunsmoor, J. E., \& Murphy, G. L. (2015). Categories, concepts, and conditioning: How humans generalize fear. Trends in Cognitive Science, 19(2), 73-77. http://dx.doi.org/10.1016/ j.tics.2014.12.003

Dymond, S., Dunsmoor, J. E., Vervliet, B., Roche, B., \& Hermans, D. (2015). Fear generalization in humans: Systematic review and implications for anxiety disorder research. Behavior Therapy, 46(5), 561-582. http://dx.doi.org/10.1016/j.beth. 2014.10.001

Filion, D. L., Dawson, M. E., \& Schell, A. M. (1993). Modification of the acoustic startle-reflex eyeblink: A tool for investigating early and late attentional processes. Biological Psychology, 35(3), 185-200. http://dx.doi.org/10.1016/03010511(93)90001-O

Grillon, C. (2002). Startle reactivity and anxiety disorders: Aversive conditioning, context, and neurobiology. Biological Psychiatry, 52(10), 958-975. http://dx.doi.org/10.1016/ S0006-3223(02)01665-7

Haselgrove, M., Aydin, A., \& Pearce, J. M. (2004). A partial reinforcement extinction effect despite equal rates of reinforcement during Pavlovian conditioning. Journal of Experimental Psychology: Animal Behavior Processes, 30(3), 240-250. http://dx.doi.org/10.1037/0097-7403.30.3.240

Honig, W. K., \& Urcuioli, P. J. (1981). The legacy of Guttman and Kalish (1956): 25 years of research on stimulusgeneralization. Journal of the Experimental Analysis of Behavior, 36(3), 405-445. http://dx.doi.org/10.1901/jeab. 1981.36-405

Kalish, H. I. (1969). Stimulus generalization. In M. H. Marx (Ed.), Learning processes (pp. 207-297). New York, NY: Macmillan.

Lang, P. J., Bradley, M. M., \& Cuthbert, B. N. (1998). Emotion, motivation, and anxiety: Brain mechanisms and psychophysiology. Biological Psychiatry, 44(12), 1248-1263. http://dx.doi.org/10.1016/S0006-3223(98)00275-3

Lang, P. J., Davis, M., \& Ohman, A. (2000). Fear and anxiety: Animal models and human cognitive psychophysiology. Journal of Affective Disorders, 61(3), 137-159. http://dx.doi. org/10.1016/S0165-0327(00)00343-8

Lipp, O. V., Cox, D., \& Siddle, D. A. (2001). Blink startle modulation during anticipation of pleasant and unpleasant stimuli. Journal of Psychophysiology, 15(3), 155. http://dx. doi.org/10.1027//0269-8803.15.3.155

Meulders, A., Harvie, D. S., Bowering, J. K., Caragianis, S., Vlaeyen, J. W. S., \& Moseley, G. L. (2014). Contingency learning deficits and generalization in chronic unilateral hand pain patients. Journal of Pain, 15(10), 1046-1056. http://dx. doi.org/10.1016/j.jpain.2014.07.005

Meulders, A., Harvie, D. S., Moseley, G. L., \& Vlaeyen, J.W. S. (2015). Generalization of pain-related fear using a left-right hand judgment conditioning task. Behavior Therapy, 46(5), 699-716. http://dx.doi.org/10.1016/j.beth.2015.02.004

Meulders, A., Vandebroek, N., Vervliet, B., \& Vlaeyen, J. W. (2013). Generalization gradients in cued and contextual painrelated fear: An experimental study in healthy participants. Frontiers in Human Neuroscience, 7, 345. http://dx.doi.org/ 10.3389/fnhum.2013.00345

Meulders, A., Vansteenwegen, D., \& Vlaeyen, J. W. (2011). The acquisition of fear of movement-related pain and associative learning: A novel pain-relevant human fear conditioning paradigm. Pain, 152(11), 2460-2469. http://dx.doi.org/10. 1016/j.pain.2011.05.015

Meulders, A., \& Vlaeyen, J. W. S. (2012). Reduction of fear of movement-related pain and pain-related anxiety: An associative learning approach using a voluntary movement paradigm. Pain, 153(7), 1504-1513. http://dx.doi.org/10.1016/j.pain. 2012.04.013 
Meulders, A., \& Vlaeyen, J. W. S. (2013). The acquisition and generalization of cued and contextual pain-related fear: An experimental study using a voluntary movement paradigm. Pain, 154(2), 272-282. http://dx.doi.org/10.1016/j.pain.2012. 10.025

Poulton, R., \& Menzies, R. G. (2002). Non-associative fear acquisition: A review of the evidence from retrospective and longitudinal research. Behaviour Research and Therapy, 40(2), 127-149. http://dx.doi.org/10.1016/S0005-7967(01)00045-6

Rosenthal, J. A. (1996). Qualitative descriptors of strength of association and effect size. Journal of Social Service Research, 21(4), 37-59. http://dx.doi.org/10.1300/J079v21n04_02

Schell, A. M., Wynn, J. K., Dawson, M. E., Sinaii, N., \& Niebala, C. B. (2000). Automatic and controlled attentional processes in startle eyeblink modification: Effects of habituation of the prepulse. Psychophysiology, 37(4), 409-417. http://dx.doi.org/10.1111/1469-8986.3740409

Schurr, B. C., \& Runquist, W. N. (1973). Acquisition and extinction of human eyelid conditioned response as a function of schedule of reinforcement and unconditioned stimulus intensity under two masked conditioning procedures. Journal of Experimental Psychology, 101, 398-401. http://dx.doi.org/ 10.1037/h0035234

Soeter, M., \& Kindt, M. (2010). Dissociating response systems: Erasing fear from memory. Neurobiology of Learning and Memory, 94(1), 30-41. http://dx.doi.org/10.1016/j.nlm. 2010.03.004

Spruyt, A., Clarysse, J., Vansteenwegen, D., Baeyens, F., \& Hermans, D. (2010). Affect 4.0: A free software package for implementing psychological and psychophysiological experiments. Experimental Psychology, 57(1), 36-45. http://dx.doi. org/10.1027/1618-3169/a000005

Vansteenwegen, D., Iberico, C., Vervliet, B., Marescau, V., \& Hermans, D. (2008). Contextual fear induced by unpredictability in a human fear conditioning preparation is related to the chronic expectation of a threatening US. Biological Psychology, 77(1), 39-46. doi:S0301-0511(07)00148-2[pii]10.1016/ j.biopsycho.2007.08.012

Vervliet, B., Kindt, M., Vansteenwegen, D., \& Hermans, D. (2010). Fear generalization in humans: Impact of verbal instructions. Behaviour Research and Therapy, 48(1), 38-43. http://dx.doi.org/10.1016/j.brat.2009.09.005

Vlaeyen, J. W. (2015). Learning to predict and control harmful events: Chronic pain and conditioning. Pain, 156 (Suppl. 1), S86-S93. http://dx.doi.org/10.1097/j.pain.0000000 000000107

Vlaeyen, J. W., de Jong, J., Geilen, M., Heuts, P. H., \& van Breukelen, G. (2001). Graded exposure in vivo in the treatment of pain-related fear: A replicated single-case experimental design in four patients with chronic low back pain. Behaviour Research and Therapy, 39(2), 151-166. http://dx.doi.org/10.1016/S0005-7967(99)00174-6

Received: December 14, 2015

AcCePted: November 28, 2016

Available online: 5 December 2016 